\title{
TECNOLOGIAS EMERGENTES COMO POSSIBILIDADES DE INOVAÇÃO NA EDUCAÇÃO
}

\author{
Graziela de Souza Sombrio ${ }^{1}$ \\ Vania Ribas Ulbricht ${ }^{2}$
}

\begin{abstract}
RESUMO: Estamos vivenciando um momento em que as tecnologias estão cada vez mais presentes no nosso cotidiano. Na educação não é diferente. A necessidade de inovação com o intuito de melhorar o processo de ensino-aprendizagem faz parte do mundo moderno. Falar em inovação sem falar em tecnologia é praticamente impossível. Desta forma, este artigo traz as tecnologias emergentes na educação e faz uma análise de como algumas delas estão sendo implantadas.
\end{abstract}

Palavras-chave: tecnologia. Inovação. Educação.

ABSTRACT: We have experienced a moment when the technologies are progressively present in our daily lives. In education is not different. The need of innovation in order to improve teaching and learning process is part of the modern world. Talking about innovation without talking about the emergent technologies is almost impossible. Accordingly, this article brings emerging technologies in education and an analysis of how some of them have been implemented.

Keywords: technologies, innovation, education.

RESUMEN: Vivimos en una época en que las tecnologías son cada vez más presentes en nuestra vida cotidiana. En la educación no es diferente. La necesidad de la innovación con el fin de mejorar el proceso de enseñanza y aprendizaje es parte del mundo moderno. Hablando de la innovación por no hablar de la tecnología es prácticamente imposible. Por lo tanto, este artículo trae las nuevas tecnologías en la educación y el análisis de cómo algunos de ellos se están aplicando.

Palabras clave: la tecnología, la innovación, la educación.

\footnotetext{
${ }^{1}$ Mestre em Matemática, Instituto Federal de Santa Catarina - Campus Xanxerê - graziela.sombrio@ifsc.edu.br

${ }^{2}$ Docente da Pós-graduação em engenharia do Conhecimento, Universidade Federal de Santa Catarina, E-mail: vrulbricht@gmail.com
}

ReLAInEP - Revista Latino-America de Inovação e Engenharia de Produção, Curitiba, PR, Brasil, v. 3, n. 4, p. 63-73, 2015. 


\section{ReLAInEP}

\section{INTRODUÇÃO}

Muito se houve falar em inovação. Principalmente no mundo atual em que vivemos, onde a velocidade da informação faz com que possamos ter acesso rápido ao que acontece no mundo. Embora nos remetessem às tecnologias quando pensamos em inovação, inovar não significa necessariamente, fazer uso delas. Porém, é contraditório separar esses dois termos.

Inovar é um conceito que não está atrelado apenas às empresas, é preciso pensar em inovação também na educação.

Os atuais estudantes da Educação Básica são nativos digitais e tem acesso às tecnologias com muito mais facilidade que as gerações anteriores. Podemos afirmar que "são conectados" o tempo todo e fazem uso das tecnologias, principalmente para diversão. Possuem dificuldade em assistir uma aula como meros ouvintes, pois precisam estar sempre "informados" do que acontece fora da sala de aula, na maioria das vezes através de redes sociais.

Estudos são feitos sobre as tecnologias emergentes e como elas podem ser utilizadas na educação. Documentos como o Horizon Report fazem estes estudos e apontam tendências e desafios a serem enfrentados. Com base em um desses documentos, analisamos neste artigo as tecnologias emergentes que tinham o prazo de adoção até 2014.

\section{INOVAÇÃO E TECNOLOGIAS NA EDUCAÇÃO}

Na sua noção mais abrangente, inovação significa novidade ou renovação, aplicada aos inúmeros aspectos relacionados à criatividade humana.

Mazza (2014) lembra que inovação deriva do latim innovare, que simplesmente significa incorporar, trazer para dentro, inserir o novo, a novidade. Já para a 3M, inovação é quando uma ideia atende às necessidades e expectativas do mercado, é viável do ponto de vista econômico e sustentável e oferece retorno financeiro às empresas.

Para Vasconcelos (2009) inovação é a capacidade de mudar um cenário, de revolucionar, por mais simples que seja a ideia inovadora, se ela for capaz de revolucionar trará um ganho imenso para aquele que executou a inovação, e permitirá a este ter uma melhor posição no espaço em que ele convive.

ReLAInEP - Revista Latino-America de Inovação e Engenharia de Produção, Curitiba, PR, Brasil, v. 3, n. 4, p. 63-73, 2015. 


\title{
ReLAInEP
}

Podemos então afirmar que para algo ser inovador é necessário ser novidade, atender às demandas de mercado e ser aceito por seus consumidores. É engano achar que precisa ser grandioso, ou seja, algo inovador pode ser uma coisa simples, não tecnológica, mas que seja novo atenda alguma necessidade e seja aceito pelo público. Embora nos reportassem à tecnologia quando falamos em inovação, nenhum dos conceitos acima, faz essa analogia.

Por outro lado, precisamos considerar que o mundo passa por transformações constantes. Entretanto, as transformações tecnológicas, principalmente às ligadas ao mundo virtual, são os mais presentes no dia-a-dia das pessoas. Hoje, o acesso à internet ficou muito mais facilitado e com isso, estamos cada vez mais conectados.

Os jovens de hoje, que representam a maior parte dos alunos, são considerados nativos digitais.

\begin{abstract}
Se a geração $\mathrm{Y}^{3}$ foi denominada pela tecnologia, a geração é denominada pela velocidade de tecnologia. Por isso, são extremamente impacientes, querem tudo instantaneamente. Os jovens $\mathrm{Z}^{4}$ cresceram vendo o desenvolvimento da Web 2.0, termo utilizado para descrever uma segunda ascendência da Internet. Essa ascensão não se refere a uma nova especificação técnica da Web, mas a uma mutação na forma como ela é encarada por usuários e desenvolvedores, tendência que reforça o conceito de troca ininterrupta de informações. (FAVA, 2014, p. 59)
\end{abstract}

Já é de senso comum que a escola precisa acompanhar essas mudanças, ou seja precisa inovar de forma a melhorar a qualidade do processo de ensino e aprendizagem e capacitar de forma integral seus alunos, considerando também a formação ética e cidadã.

O mundo do trabalho procura por profissionais que não sejam apenas especialistas em um determinado conteúdo, mas sim que sejam criativos, inovadores e líderes.

Reflexões sobre a forma como a escola está lidando com as mudanças, como as práticas docentes estão sendo realizadas, como está sendo dada a formação continuada dos professores, precisam ser constantes. Para isto, gestores e professores precisam estar abertos às possibilidades de mudanças, de comportamentos e até mesmo, de competências. Com o mundo globalizado e o fácil acesso à informação, o professor deixa de ser o "proprietário do conhecimento" e o único a transmiti-los para os alunos. Ele passa a ser mediador no processo de ensino e aprendizagem. Entretanto, Fava (2014, p. 101) afirma que as escolas, que deveriam ser bancos de talentos, incubadoras do futuro, não estão cumprindo seu papel.

\footnotetext{
${ }^{3}$ Nascidos depois de 1980 e até meados de 1990.

${ }^{4}$ Nascidos no início da década de 1990 até os dias de hoje.
}

ReLAInEP - Revista Latino-America de Inovação e Engenharia de Produção, Curitiba, PR, Brasil, v. 3, n. 4, p. 63-73, 2015. 


\section{ReLAInEP}

Para Gabriel (2013, p. 7), a tecnologia não é o diferencial, mas o modo com utilizamos, sim. É preciso ter metodologias de ensino adequadas, pois caso contrário, muitas se tornam apenas diversão, tornando-se uma ferramenta negativa para o processo de ensino e aprendizagem.

Desde 2002 o $\mathrm{NMC}^{5}$, através do Projeto Horizon, divulga três relatórios, dos quais dois deles tratam das tecnologias emergentes na educação. Para chegar a estes relatórios, um grupo de especialistas de renome internacional, é consultado e, a partir de discussões realizadas, escolhem quais são as tecnologias a serem destaque. Paralelo às tecnologias, são citados também os principais desafios que serão enfrentados. O Horizon Report - Edição K-12 $2013^{6}$ traz dentre os desafios:

- - o desenvolvimento profissional contínuo precisa ser valorizado e integrado na cultura das escolas;

- - as próprias práticas educacionais limitam a absorção mais ampla das novas tecnologias;

- $\quad$ novos modelos de educação estão trazendo competição sem precedentes para os modelos tradicionais de educação.

O uso de tecnologias na educação é uma forma de inovar, de ter alunos e, consequentemente, profissionais, mais criativos e com isso, mais preparados para o mundo do trabalho. Como educadores trabalhamos para que tenhamos educação de qualidade em todos os níveis. Moran, Masetto, Behrens resumem o que seria uma educação de qualidade no texto abaixo.

Uma educação de qualidade envolve muitas variáveis:

- uma organização inovadora ${ }^{7}$, aberta, dinâmica, com um projeto pedagógico coerente, aberto participativo; com infraestrutura adequada, atualizada, confortável; tecnologias acessíveis, rápidas e renovadas;

- uma organização que congrega docentes bem preparados intelectual, emocional, comunicacional e eticamente; bem remunerados, motivados e com boas condições profissionais, e onde haja circunstâncias favoráveis a uma relação efetiva com os alunos que facilite conhecê-los, acompanhá-los, orientá-los;

- uma organização que tenha alunos motivados e preparados, intelectual e emocionalmente, com capacidade de gerenciamento pessoal e grupal. (MORAN, MASETTO, BEHRENS, 2013, p. 23)

\footnotetext{
${ }^{5}$ New Media Consortion

${ }^{6} \mathrm{~K}$-12 é o relatório referente à Educação Básica

${ }^{7}$ Grifo nosso
}

ReLAInEP - Revista Latino-America de Inovação e Engenharia de Produção, Curitiba, PR, Brasil, v. 3, n. 4, p. 63-73, 2015. 


\section{ReLAInEP}

Em 2012, o NMC em parceria com o Sistema FIRJAN, reuniu 30 especialistas para, a partir da metodologia utilizada no Projeto Horizon, identificassem as tecnologias emergentes para a Educação Básica no Brasil num espaço de 5 anos.

Figura 1 - Tecnologias emergentes para a Educação Básica no Brasil

\begin{tabular}{|c|c|}
\hline \multirow{4}{*}{$\begin{array}{c}\text { Tempo de adoção: } 1 \text { ano ou } \\
\text { menos }\end{array}$} & Ambientes colaborativos \\
\cline { 2 - 2 } & Aprendizagem baseada em jogos \\
\cline { 2 - 2 } & Dispositivos móveis - celulares \\
\cline { 2 - 2 } & Dispositivos móveis - tablets \\
\cline { 2 - 2 } Tempo de adoção: 2 a 3 anos & Geolocs de celular \\
\cline { 2 - 2 } & Aplicativos móveis \\
\cline { 2 - 2 } & Conteúdo livre \\
\cline { 2 - 2 } & Inteligência coletiva \\
\cline { 2 - 2 } Tempo de adoção: 4 a 5 anos & Laboratórios móveis \\
\cline { 2 - 3 } & Ambientes pessoais de aprendizagem \\
\cline { 2 - 3 } & Aplicações semânticas \\
\hline
\end{tabular}

Fonte: Horizon Report - 2012 - Panorama Tecnológico para o Ensino Fundamental e Médio Brasileiro

Figura 2 - Principais tendências e principais desafios para a Educação Básica

\section{Principais tendências $\quad$ Principais desafios}

Os paradigmas do ensino estão se modificando para $\mathrm{A}$ formação dos professores deveria ser incluir modelos de aprendizado online, híbridos e modificada para ser adaptada aos novos colaborativos. estudantes e às novas tecnologias.

A abundância de recursos e relacionamentos aos quais a internet facilitou o acesso está nos desafiando cada vez mais a revisitar nossos papéis como educadores.

Utilizar a tecnologia não é suficiente, também é necessário modificar as metodologias de ensino.

As pessoas esperam poder trabalhar, aprender e $\mathrm{O}$ programa educacional precisa ser estudar sempre que quiserem e de onde estiverem. reinventado.

As escolas estão cada vez mais explorando Incorporar experiências da vida real no tecnologias que permitem que professores e alunos colaborem de forma mais eficientes. aprendizado nem sempre acontece, e quando acontece, não são valorizados.

A crescente disponibilidade de banda larga modificará de forma dramática os comportamentos dos usuários durante o ensino, aprendizado e pesquisa durante os próximos cinco anos.

O Brasil precisa de uma infraestrutura melhor para fazer uma utilização completa da Internet. 


\section{ReLAInEP}

As tecnologias que utilizamos estão cada vez mais baseadas na nuvem e nossas noções de suporte de TI são descentralizadas.

As pessoas têm necessidade de compartilhar - muitas vezes publicamente.

Cada vez mais estudantes querem usar sua própria tecnologia para o aprendizado.

Existe uma nova ênfase na sala de aula em relação a um aprendizado mais ativo e mais baseado em desafios.

Os computadores, como os conhecemos, estão em processo de uma sólida reinvenção

As métricas apropriadas de avaliação não atendem a emergência de novas formas acadêmicas de autoria, publicação e pesquisa.

As escolas precisam abraçar à crescente mistura de aprendizado formal e informal.

A qualidade do ensino público precisa ser melhorada.

Muitas atividades relacionadas ao aprendizado e ensino ocorrem fora das salas de aula e, assim, não são parte das métricas de ensino tradicionais.

Colocar a tecnologia do século 21 em escolas do século 19 é um verdadeiro empreendimento.

Fonte: Horizon Report - 2012 - Panorama Tecnológico para o Ensino Fundamental e Médio Brasileiro

A partir deste relatório, produzido em 2012, vamos analisar a utilização daqueles cujo tempo de adoção era de 1 ano ou menos, nas escolas do país. O objetivo é buscar dados que mostrem se essas tecnologias estão ou não sendo utilizadas de forma efetiva.

\subsection{Ambientes Colaborativos}

Um ambiente colaborativo de aprendizagem é um espaço de construção coletiva de conhecimento. Embora não esteja relacionado com o uso de tecnologias, com a internet novos espaços online são criados, na maioria das vezes utilizando o conceito de nuvem. Possibilita o compartilhamento de ideias, experiências e materiais.

Neste contexto, de acordo com Pino (1999), é preciso:

- a flexibilidade dos papeis e movimentos no processo das comunicações e relações que fazem a mediação da aprendizagem;

- a valorização das diferentes autorias do professor/organizador, monitor e alunos participantes;

- a democratização das participações nos diferentes espaços do ambiente e da inserção de colaborações individuais e coletivas dos grupos de trabalho;

- alcance de metas realizadas coletivamente;

- debates que privilegiam novas leituras, interpretações, associações e críticas em espaços formais e informais;

- suporte aos estudos individuais.

ReLAInEP - Revista Latino-America de Inovação e Engenharia de Produção, Curitiba, PR, Brasil, v. 3, n. 4, p. 63-73, 2015. 


\section{ReLAInEP}

O Ministério da Educação e o Ministério da Ciência e Tecnologia criaram o Portal do Professor. Por meio desta ferramenta é possível a participação em fóruns de discussão em temas variados ligados à educação.

\subsection{Aprendizagem baseada em jogos}

De acordo com o Horizon Report - 2013, a medida que a cultura dos jogos está crescendo, a idade média dos jogadores está diminuindo. Antes, o que era visto como apenas instrumento de diversão, hoje pode (e deve) ser utilizado como ferramenta de motivação. Hoje, grande parte das crianças e dos jovens joga algum tipo de jogo semanalmente. Estes, responsáveis por prender a atenção do aluno e estimular a concentração, são uma possibilidade de "aprender brincando".

O jogo sugere amplas possibilidades de exercício do potencial criativo dos envolvidos diretamente com ele, já que é um campo fértil para a semente da imaginação. $\mathrm{O}$ ato de jogar requer toques de criatividade, assim como a criatividade desponta na realização do jogo. (MIRANDA, 2002)

Podemos citar como exemplo no Brasil, a plataforma Kiduca. É uma plataforma educacional, baseada em games e fundamentada nas diretrizes curriculares nacionais que motiva professores e alunos do Ensino Fundamental a estudar ${ }^{8}$. A Kiduca está apostando no financiamento coletivo para atingir 2500 alunos do ensino público de Sorocaba e regiões próximas. O objetivo é disponibilizar a ferramenta e o suporte técnico durante um ano para 5 instituições selecionadas.

\subsection{Celulares}

O uso de celulares é um assunto polêmico. De um lado alguns governantes e educadores proíbem seu uso em salas de aula, por outro é uma das tecnologias emergentes para a sala de aula. A Unesco elaborou um documento no qual recomenda o uso destes aparelhos em salas

\footnotetext{
${ }^{8}$ Fonte: http://www.kiduca.com.br/kiduca/
}

ReLAInEP - Revista Latino-America de Inovação e Engenharia de Produção, Curitiba, PR, Brasil, v. 3, n. 4, p. 63-73, 2015. 


\section{ReLAInEP}

de aula para fins educacionais. As figuras 1 e 2 mostram as recomendações aos governantes e os motivos para uso de celulares ${ }^{9}$ :

Figura 3: Recomendação aos governos

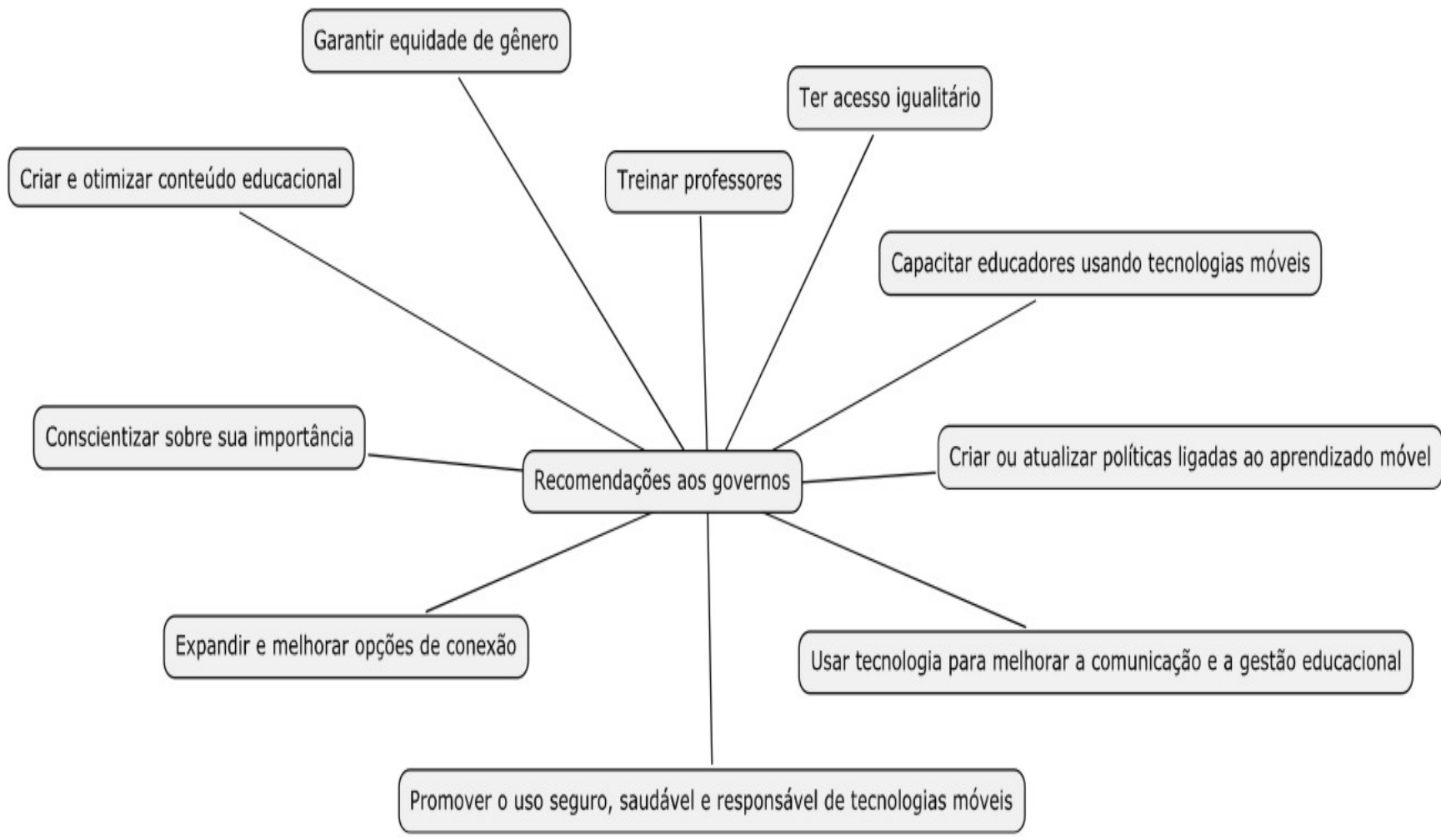

Fonte:http://ultimosegundo.ig.com.br/educacao/2013-03-03/unesco-recomenda-o-uso-de-celularescomo-ferramenta-de-aprendizado.html

Os celulares já são utilizados em algumas partes do mundo como facilitadores do acesso à informação e à educação. Além disto, pode ser uma ferramenta que possibilite a inclusão de pessoas com deficiência e que facilite o aprendizado personalizado, considerado também uma das tendências em educação.

\footnotetext{
${ }^{9} \mathrm{O}$ documento na íntegra está disponível em http://unesdoc.unesco.org/images/0021/002196/219641e.pdf
}

ReLAInEP - Revista Latino-America de Inovação e Engenharia de Produção, Curitiba, PR, Brasil, v. 3, n. 4, p. 63-73, 2015. 


\section{ReLAInEP}

Figura 4: Recomendação para uso do celular na aprendizagem

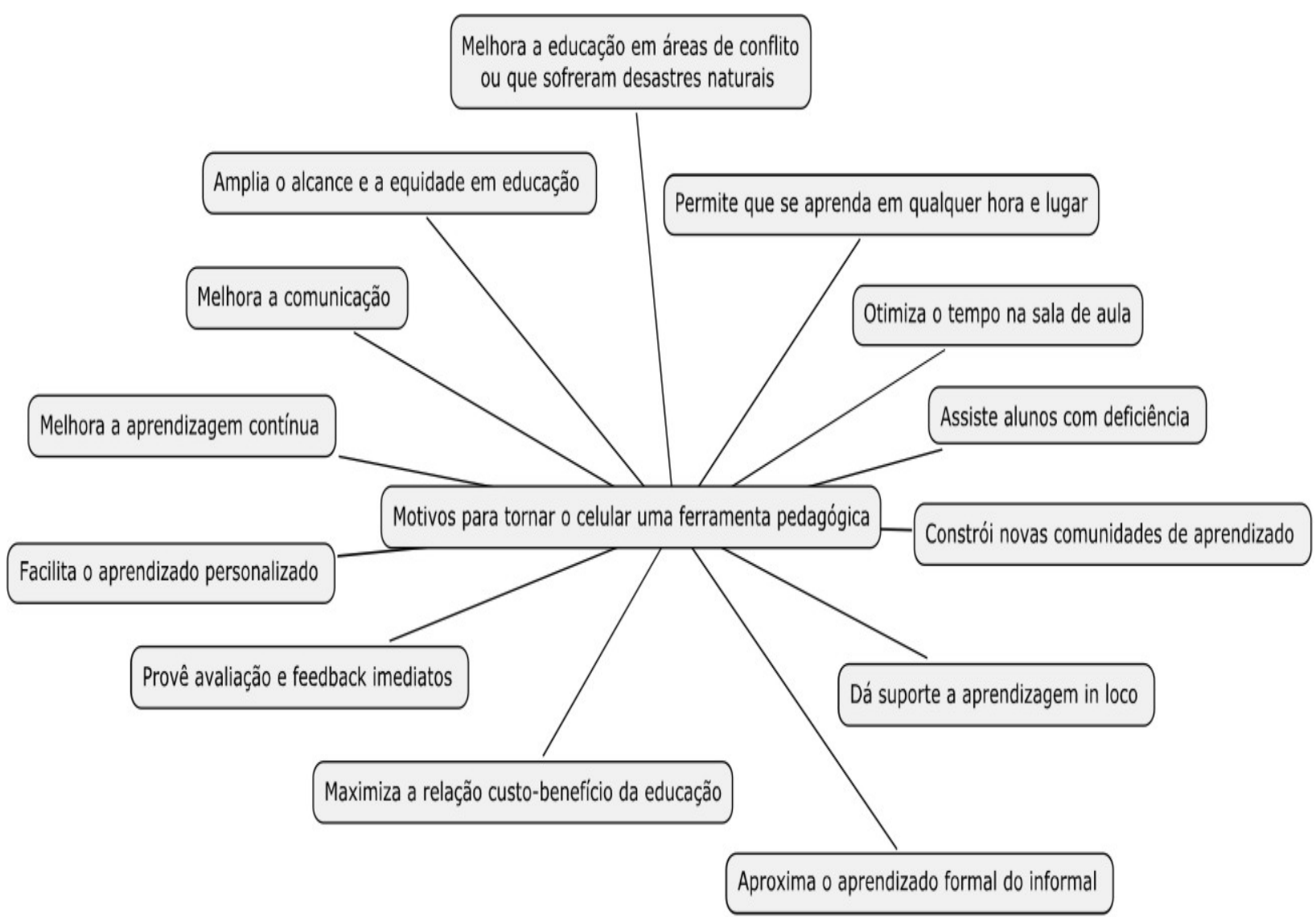

Fonte:http://ultimosegundo.ig.com.br/educacao/2013-03-03/unesco-recomenda-o-uso-de-celularescomo-ferramenta-de-aprendizado.html - Figura produzida pelas autoras

\subsection{Tablets}

Muitas escolas já utilizam os tablets como substitutos do livro impresso. Amábile Pacios , presidente da Federação Nacional de Escolas Particulares (Fenep), estima que 30\% das escolas particulares do país adotam, de alguma forma, o tablet em sala de aula.

Já Luiz Cláudio Megiorin, presidente da Associação de Pais e Alunos do Distrito Federal, relata a apreensão dos pais, pois afirmam que não sabem quando o filho está estudando ou quando está apenas se divertindo. Além disso, ele afirma que é necessário aliar teoria e prática e acredita que o uso do tablet por si só não é o suficiente para atrair a atenção do estudante.

O fato é que o uso de tablets ainda é modesto. De acordo com o Portal Todos pela educação, ainda não existe conteúdo curricular adequado, há resistência por parte dos professores e custo elevado. Neste ano o MEC promete distribuir 500 mil tablets e as editoras

ReLAInEP - Revista Latino-America de Inovação e Engenharia de Produção, Curitiba, PR, Brasil, v. 3, n. 4, p. 63-73, 2015. 


\section{ReLAInEP}

de livros didáticos para as escolas públicas precisam produzir o conteúdo também em formato digital.

No ano de 2013 foi aprovado no Senado Federal o Projeto de Lei 109/2013. Este projeto determina a disponibilidade de tablets para o uso individual dos estudantes das escolas públicas de educação básica, até 2013. Conforme o projeto, os tablets serão distribuídos para todos os alunos a partir do sexto ano do Ensino Fundamental, até a conclusão do Ensino Médio. Considerando o avanço tecnológico, o projeto prevê a substituição dos tablets por equipamentos similares, porém mais atuais. Prevê também a capacitação dos professores através de cursos de aperfeiçoamento. Este projeto está atualmente na Comissão de Educação.

É preciso considerar que o tablet não pode ser visto apenas como substituto para o livro didático. Ele possui ferramentas que permitem o uso de vídeos e imagens, baixar aplicativos e conteúdos que possam ser utilizados como complementação aos livros didáticos.

\section{CONSIDERAÇÕES FINAIS}

Este texto mostra a forma como algumas tecnologias estão sendo implantadas nas escolas. Sabemos que o assunto está longe de ser esgotado, até porque nem todas essas tecnologias são bem aceitas pela sociedade. Talvez essa não aceitação seja pela falta de conhecimento, pois algumas têm sua maior utilização na diversão.

Fica claro que antes do uso de qualquer tecnologia é preciso que os professores sejam capacitados para que possam fazer o uso adequado e, consequentemente, inovar em suas metodologias de ensino. É preciso ainda uma mudança de comportamento de toda a comunidade escolar, pois muitas vezes não é fácil aceitar o novo, inovar em suas atividades. Porém grande parte dos alunos tem acesso a muitas tecnologias e fazem uso delas frequentemente, mas não com objetivos educacionais. Temos então uma oportunidade de despertar o interesse desses alunos nas diversas áreas do conhecimento, aliando tecnologia e inovação à educação.

ReLAInEP - Revista Latino-America de Inovação e Engenharia de Produção, Curitiba, PR, Brasil, v. 3, n. 4, p. 63-73, 2015. 


\section{ReLAInEP}

\section{REFERENCIAS}

AQUINO, Yara. Escolas particulares adotam tablets em substituição ao livro impresso. 2014. Disponível em: <http://memoria.ebc.com.br/agenciabrasil/noticia/2014-01-17/escolas-particularesadotam-tablets-em-substituicao-ao-livro-impresso>. Acesso em: 07 set. 2014.

FAVA, Rui. Educação 3.0. 1 ed, São Paulo: Saraiva, 2014.

GABRIEL, Martha. Educ@ar: a (r)evolução digital na educação. São Paulo: Saraiva, 2013. 241 p.

GOVERNO impulsiona uso de tablets na escola. 2014. Disponível em $<$ http://www.todospelaeducacao.org.br/educacao-na-midia/indice/29338/governo-impulsiona-uso-detablet-na-escola/?pag=ultima>. Acesso em: 07 set. 2014.

JOHNSON, L.; ADAMS Becker, S.; CUMMINS, M.; ESTRADA, V.; FREEMAN, A.; LUDGATE, H. NMC Horizon Report: Edição Ensino Superior 2013. Tradução para o português por Ez2translate. Austin, Texas: O New Media Consortium.

JOHNSON, L.; ADAMS Becker, S.; CUMMINS, M.; ESTRADA, V.; FREEMAN, A.; LUDGATE, H (2013). NMC Horizon Report: Edição K12 2013.Tradução para o português pela Ez2translate. Austin, Texas: The New Media Consortium.

LUCENA, Cícero. PLS - PROJETO DE LEI DO SENADO, Nº 109 de 2013. 2013. Disponível em: $<$ http://www.senado.gov.br/atividade/materia/detalhes.asp?p_cod_mate=111979>. Acesso em: 08 set. 2014.

MAZZA, Chael Luigi de Souza. Afinal o que é inovação? 2014. Disponível em: <http://www.portaleducacao.com.br/administracao/artigos/56629/afinal-o-que-e-inovacao >. Acesso em: 06 set. 2014.

MIRANDA, Simão de. No fascínio do jogo, a alegria de aprender. Linhas críticas, Brasília, v. 8, n. 14, p. 21-34, Jan/Jun , 2002.2014 Disponível <http://seer.bce.unb.br/index.php/linhascriticas/article/viewFile/6493/5248>. Acesso em: abr. 2014.

MORAN, José Manuela; MASETTO, Marcos T.; BERHENS, Marilda Aparecida. Novas tecnologias e mediação pedagógica. 21. ed. Campinas: Papirus, 2013. 171 p. (Coleção Papirus Educação).

PERSPECTIVAS tecnológicas para o ensino fundamental e Médio Brasileiro de 2012 a 2017: uma análise regional por NMC Horizon Project . Austin, Texas: The New Media Consortium Estados Unidos, 2012.

PINO, Angel et al. Bases Preliminares para um Ambiente Colaborativo de Aprendizagem. 1999. Disponível em: <http://www.lite.fe.unicamp.br/sapiens/>. Acesso em: 08 set. 2014.

VASCONCELOS, Eduardo. O que realmente significa a palavra "inovação"? 2009. Disponível em: $<$ http://eduardovasconcelos.wordpress.com/2009/05/10/o-que-realmente-significa-a-palavra"inovacao"/>. Acesso em: 07 set. 2014.

ReLAInEP - Revista Latino-America de Inovação e Engenharia de Produção, Curitiba, PR, Brasil, v. 3, n. 4, p. 63-73, 2015. 
ReLAInEP - Revista Latino-America de Inovação e Engenharia de Produção, Curitiba, PR, Brasil, v. 3, n. 4, p. 63-73, 2015. 